\title{
Peripheral Neuropathy under Infliximab Therapy: About One Case
}

\author{
Fatima-Zahra Hamdoun, Hakima Abid, Nada Lahmidani, Mounia El Yousfi, \\ Dafr-Allah Benajah, Mohammed El Abkari, Adil Ibrahimi
}

Department of Hepato-Gastroenterology, Hassan II University Hospital of Fez, Faculty of Medicine, University Sidi Mohammed Ben Abdelalh, Fez, Morocco

Email: fatimazahrahamdoun@hotmail.com

How to cite this paper: Hamdoun, F.-Z., Abid, H., Lahmidani, N., El Yousfi, M., Benajah, D.-A., El Abkari, M. and Ibrahimi, A. (2020) Peripheral Neuropathy under Infliximab Therapy: About One Case. Open Journal of Gastroenterology, 10, 242-246. https://doi.org/10.4236/ojgas.2020.109023

Received: July 11, 2020

Accepted: September 24, 2020

Published: September 27, 2020

Copyright (c) 2020 by author(s) and Scientific Research Publishing Inc. This work is licensed under the Creative Commons Attribution International License (CC BY 4.0).

http://creativecommons.org/licenses/by/4.0/

\begin{abstract}
A-TNF inhibitors are increasingly used in various inflammatory disorders. Multiple side effects have been reported in recent years, particularly peripheral neuropathies. We report a case of axonal neuropathy occurring after the start of treatment with Infliximab. This is a 47 years old patient, followed for Crohn's disease requiring treatment with Infliximab. Twenty-two weeks later, the patient presented a grade 4 of axonal neuropathy. We concluded to a medicinal sensitive neuropathy after elimination of other etiologies. Given the severity of the neurological symptoms, we decided to change the therapeutic class.
\end{abstract}

\section{Keywords}

Crohn's Disease, Infliximab, Peripheral Neuropathy

\section{Introduction}

A-TNF inhibitors treatments are commonly used for the treatment of several inflammatory disorders such as inflammatory rheumatisms (spondyloarthropathies, rheumatoid arthritis or psoriatic arthritis) and gastroenterological inflammatory diseases [1]. Among the different therapeutic classes available, there are chimeric or humanized monoclonal antibodies such as infliximab or adalimumab [1]. Among the adverse effects related to the use of these treatments, demyelinating events of the nervous system central [2] and demyelinating peripheral neuropathies [3] were reported. One study estimated that peripheral demyelinating complications could be more frequent than expected compared to central ones [4]. The occurrence of these events poses the problem of the ulterior management in the absence of clear guidelines. 


\section{Objective}

The aim of this work is to highlight related peripheral nerve complications of a-TNF inhibitors, especially peripheral demyelinating and to underline the difficulty of management in the absence of clear guidelines.

\section{Case Observation}

This is a 47 years old patient, without significant neurological history, chronic smoking weaned, followed since 2014 for Crohn's disease with ano-perineal manifestations under combotherapy (infliximab, 6-mercapthopurine) since 2018 at the recommended dose with good clinical answer and great initial tolerance. From the 6th injection of infliximab, the patient began to report the occurrence of dysesthesia with uncomfortable sensations complicated by painful cramps limiting his physical activity and prompting him to stop treatment.

The patient was hospitalized in gastroenterology department. The clinical examination at its admission founds a conscious patient with no fever. Abdominal examination did not reveal any abnormalities including no abdominal tenderness or palpable mass; the digital rectal examination was very painful. The neurological examination showed hypoesthesia in sock reaching the ankles on. Sociodemographic and clinical characteristics of the patient are summarized in Table 1.

The biological assessment revealed anemia with $8 \mathrm{~g} / \mathrm{dl}$, blood cells with 10,700 elm $/ \mathrm{mm}^{3}$, correct platelets, a high CRP at $209 \mathrm{mg} / \mathrm{l}$ and a low TP at $56 \%$. The serology of the hepatitis $\mathrm{E}$ virus, HIV and hepatitis $\mathrm{C}$ virus were requested, given the neurological manifestations, returned normal. Dosage of vitamin B 12 and folic acid were also normal.

The radiological assessment (Figure 1) showed a thickening that extends from the rectum to the left colic angle without individualisation of collection. The proctological examination revealed the presence of large external fistulous orifices placed at 1 o'clock on the anal margin with pus, sphincteric hypotonia and

Table 1. Sociodemographic and clinical characteristics of the patient.

\begin{tabular}{|c|c|}
\hline & Characteristics \\
\hline Age & 47 years \\
\hline Clinical history & $\begin{array}{l}\text { - Chronic smoking weaned } \\
\text { - followed since } 2014 \text { for Crohn's disease with } \\
\text { ano-perineal manifestations }\end{array}$ \\
\hline Admitted for & Sensitive neuropathy \\
\hline Current treatment & Combotherapy (infliximab, 6-mercapthopurine) \\
\hline Clinical & $\begin{array}{l}\text { - dysesthesia } \\
\text { - painful cramps }\end{array}$ \\
\hline Physical examination & $\begin{array}{l}\text { - no fever } \\
\text { - Digital rectal: very painful, sphincteric hypotonia } \\
\text { - Hypoesthesia in sock reaching the ankles on }\end{array}$ \\
\hline
\end{tabular}


perception at 12 o'clock of a loss of substance. Anoperineal magnetic resonance imaging (Figure 2) showed rectal thickening and sclerolipomatosis, loss of substance at 12 o'clock communicating with a perianal abscess and individualization of 2 fistulas.

Taking into account the findings of the neurological examination, an electromyogram was performed and revealed grade 4 of lower limb sensory neuropathy.

The patient was put on strong analgesic as well as vitamin complexes and benefited from fecal diversion to let the rectum rest.

Given the neurological findings and the activity of the disease, the TNF was discontinued at neuropathy onset. We proposed a therapeutic alternative to anti TNF alpha treatment to manage the inflammation on one hand and on the other hand not to further aggravate sensory neuropathy. Hence, we decide to start the Methotrexate. The treatment and its side effects were explained to the patient. The switch to Methotrexate was made with no further neurological complications. The patient was followed up for 14 months. The evolution was marked by improvement in neurological signs after 5 months with partial improvement on the digestive level.

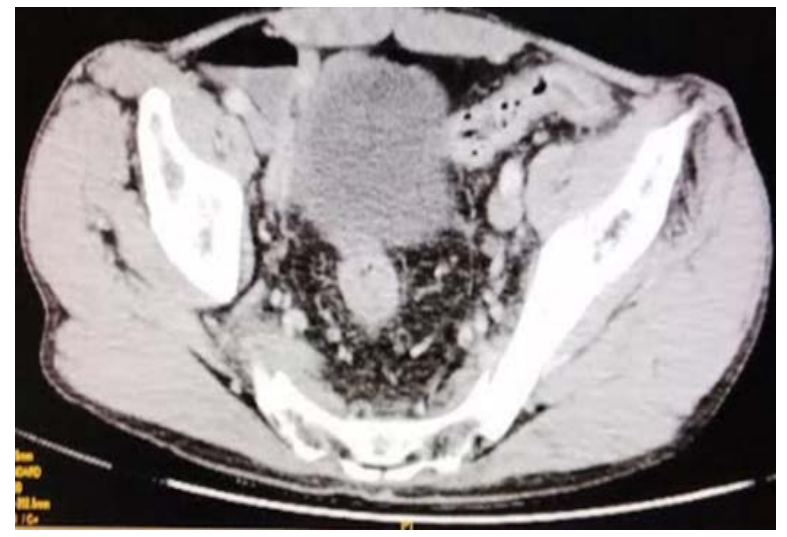

Figure 1. CT image showing inflammatory thickening that extends from the rectum to the left colic angle (at the neuropathy onset).

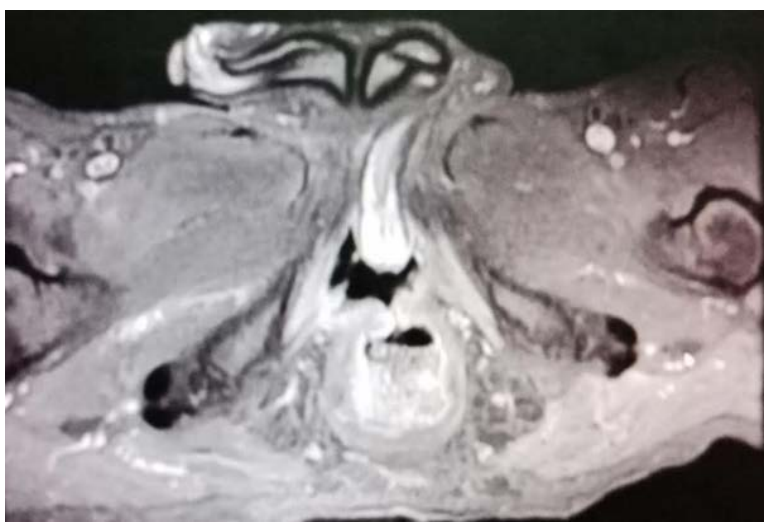

Figure 2. Image of MRI showing thickening and sclerolipomatosis, loss of substance at 12 o'clock communicating with a perianal abscess and individualization of 2 fistulas (at the neuropathy onset). 


\section{Discussion}

The occurrence of peripheral neurological adverse effects under anti-TNF alpha is a problem which prescribers may be increasingly confronted with because of the growing use of this therapeutic family [5]. The estimation impact of peripheral neuropathy during Infliximab therapy is difficult and the time to onset is often less than two years after the beginning of anti TNF alpha [1]. S. Fernández-Menéndez et al. [6] report a case of multifocal-motor-neuropathy-like disease associated with the use of Infliximab in a patient with Crohn's disease, that occured 3 years after beginning of the anti TNF. In Singer's study [7] and Rodriguez-Escalera's study [8], the sensory neuropathy of both lower limbs began after the 4th month in patient with chronic inflammatory bowel disease. In our case, the manifestations were observed after the 6 th cure. In our case, the patient began to report the occurrence of peripheral neuropathy from the 6th injection of infliximab.

The risk of neuropathy and other neurological complications varies from one anti TNF to another [5]. The decision to continue treatment with anti TNF alpha should be discussed on a case by case. Our patient has developed a grade 4 of lower limb sensory neuropathy under infliximab thing that pushed us to change this therapeutic class. In the Stubgen study's and Tsouni study's [9] [10], specific management of neuropathy by intravenous corticosteroids and immunoglobulins was necessary despite a spontaneous improvement in the symptomatology when anti TNF alpha was stopped and when there was no response to stopping anti TNF in Tsouni study's. In the case reported by Zinebi et al. [5], the evolution is partially favorable with regression almost complete of symptoms after three months of reduction in the dosage and a complete electrical recovery at the 10th month. In our case, we observed the disappearance of the neurological symptoms after 5 months from stopping the anti TNF.

Summary of patient characteristics, neuropathy, and outcome are shown in Table 2.

Table 2. Summary of patient characteristics, neuropathy, and outcome.

\begin{tabular}{|c|c|c|c|c|}
\hline & Our case & Tsouni et al. [10] & Zinebi et al. [5] & $\begin{array}{c}\text { Rodriguez-Escalera } \\
\text { et al. [8] }\end{array}$ \\
\hline Age at the presentation & 47 years & 49 years & 60 years & 34 years \\
\hline $\begin{array}{l}\text { Underlying inflammatory } \\
\text { disorder }\end{array}$ & Crohn's disease & inflammatory disorders & hemorrhagic rectocolitis & rheumatoid arthritis \\
\hline A-TNF agent used & infliximab & Infliximab/Adalimumab & infliximab & Infliximab \\
\hline A-TNF onset to neuropathy & $6^{\text {th }}$ injection & 19 months & 3 months & $4^{\text {th }}$ injection \\
\hline Treatment & a-TNF stopped & $\begin{array}{l}\text { a-TNF stopped } \\
\text { +/-intravenous } \\
\text { immunoglobulin }\end{array}$ & $\begin{array}{l}\text { reduction of the } \\
\text { dose to half }\end{array}$ & a-TNF stopped \\
\hline Neuropathy outcome & Recovered at 3 months & 3 months & 10 months & 6 months \\
\hline
\end{tabular}




\section{Conclusion}

The effectiveness of Infliximab is indisputable in gastroenterological inflammatory diseases. The reduction of the dose or the change of therapeutic class to the occurrence of an adverse effect, particularly peripheral neuropathy, must be discussed on a case-by-case.

\section{Conflict of Interest}

None of the authors has any conflict of interest, financial or otherwise.

\section{References}

[1] Cohen, M., et al. (2012) Neurological Adverse Events Under Anti-TNF Alpha Therapy. Revue Neurologique, 168, 33-39. https://doi.org/10.1016/j.neurol.2011.06.005

[2] Fernández-Espartero, M.C., Pérez-Zafrilla, B., Naranjo, A., et al. (2010) Demyelinating Disease in Patients Treated with TNF Antagonists in Rheumatology: Data from BIOBADASER, a Pharmacovigilance Database, and a Systematic Review. Seminars in Arthritis and Rheumatism, 40, 330-337. https://doi.org/10.1016/j.semarthrit.2010.06.004

[3] Lozeron, P., Denier, C., Lacroix, C. and Adams, D. (2009) Long-Term Course of Demyelinating Neuropathies Occurring during Tumor Necrosis Factor-Alpha-Blocker Therapy. Archives of Neurology, 66, 490-497. https://doi.org/10.1001/archneurol.2009.11

[4] Seror, R., et al. (2013) Pattern of Demyelination Occurring during Anti-TNF- $\alpha$ Therapy: A French National Survey. Rheumatology, 52, 868-874. https://doi.org/10.1093/rheumatology/kes375

[5] Zinebi, A., Akhouad, Y., Rkiouak, A., et al. (2016) Peripheral Neuropathy during Infliximab Therapy: A Case Study. Pan African Medical Journal, 24, Article No. 271. https://doi.org/10.11604/pamj.2016.24.271.3498

[6] Fernández-Menéndez, S., et al. (2015) Multifocal-Motor-Neuropathy-Like Disease Associated with Infliximab Treatment in a Patient with Crohn's Disease. Journal of the Neurological Sciences, 349, 246-248. https://doi.org/10.1016/j.jns.2015.01.003

[7] Singer, O.C., et al. (2004) Acute Neuropathy with Multiple Conduction Blocks after TNF-Alpha Monoclonal Antibody Therapy. Neurology, 63, 1754. https://doi.org/10.1212/01.WNL.0000142974.81103.95

[8] Rodriguez-Escalera, C., et al. (2005) Multifocal Motor Neuropathy with Conduction Block in a Patient with Rheumatoid Arthritis on Infliximab Therapy. Rheumatology (Oxford), 44, 132-133. https://doi.org/10.1093/rheumatology/keh439

[9] Stubgen, J. (2008) Tumor Necrosis Factor-Alpha Antagonists and Neuropathy. Muscle \& Nerve, 37, 281-292. https://doi.org/10.1002/mus.20924

[10] Tsouni, P., et al. (2015) Anti-TNF Alpha Medications and Neuropathy. Journal of the Peripheral Nervous System, 20, 397-402. https://doi.org/10.1111/jns.12147 